\title{
Identification of the kisspeptin cells of the arcuate nucleus as 'pulse generators' for gonadotropin releasing hormone (GnRH)
}

\author{
lain Clarke, Ahmed Ezzat, Jessica Crawshaw and Alda Pereira \\ Dept Physiology, Monash University, Melbourne
}

\section{Introduction}

GnRH is secreted in a pulsatile manner into the hypophysial portal blood.

- It has been hypothesised that there is a 'pulse generator in the brain that is responsible for the rigid pulse pattern of GnRH secretion.

- One theory is that kisspeptin cells in the arcuate nucleus of the hypothalamus constitute the GnRH pulse generator and there is circumstantial evidence for this (Ohkura et al2009 J Neuroendo 21: 813; Goodman et al 2013 Endo 154: 4259).

- These kisspeptin cells also produce dynorphin and neurokinin B and are known as KNDy cells.

KNDy cells project into the median eminence and could act on GnRH terminals (not GnRH cell bodies) to cause GnRH secretion (d'Anglemont de Tassigny 2008 Endo 149: 3926).

- Other factors such as Glutamate could also act on the GnRH terminals to elicit pulsatile secretion.

\section{Aim}

To ascertain whether KNDy cells are activated at the exact time when a secretory episode of GnRH occurs.

\section{Procedure}

Eighteen ewes were taken in the mid-luteal phase of the estrous cycle and blood samples were taken at 10 minute intervals for $3 \mathrm{~h}$ to measure plasma LH levels.

The ewes were killed and the brains perfused in $4 \%$ paraformaldehyde.

Double labelling immunohistochemistry was performed on sections through the preoptic area and the arcuate nucleus to examine c-Fos labelling in:-

- GnRH cells

- Kisspeptin cells in the preoptic area

- KNDy cells in the arcuate nucleus

- Glutamate cells in the preoptic area

- Glutamate cells in the arcuate nucleus

Double labelling for kisspeptin/GnRH and vGluT2 (a marker of glutamate cells and projections) was performed on sections of the median eminence to demonstrate close association between neurosecretory terminals for kisspeptin and $\mathrm{GnRH}$ as well as glutamate $\& \mathrm{GnRH}$.

\section{Results}

Three sheep displayed an LH pulse when the brains were collected (Fig 1). These and 3 other sheep that did not display a pulse at brain collection were used.

Fig 1: Sheep either displaying an LH pulse or no LH pulse at the time of brain collection (examples).
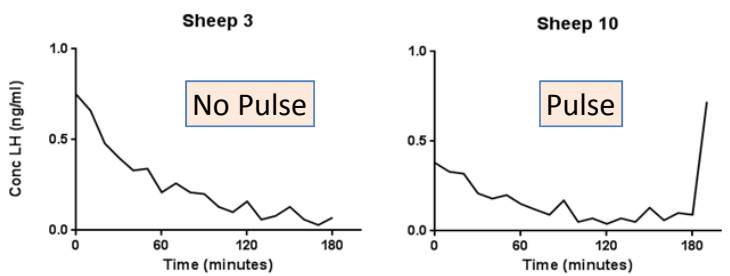

Table 1: Fos labelling was higher in the 'pulse' sheep than in the 'no-pulse sheep in KNDy cells and arcuate glutamate cells, but not in GnRH cells nor in preoptic glutamate cells.

\begin{tabular}{lllll} 
& No pulse & Pulse & Significance (t-test) \\
\hline GnRH & $29.7 \pm 8.0$ & $34.5 \pm 4.3$ & NS \\
\hline Kiss - POA & $5 \pm 0.6$ & $4.3 \pm 1.7$ & NS \\
\hline KNDy - ARC & $34.4 \pm 6.1$ & $74.9 \pm 2.5$ & 0.002 \\
\hline Glutamate - POA & $5.9 \pm 0.6$ & $5.9 \pm 0.7$ & NS \\
\hline Glutamate - ARC & $5.8 \pm 0.5$ & $27.6 \pm 3.6$ & 0.014
\end{tabular}

Fig 2: GnRH (red) \& kisspeptin (green) terminals in the neurosecretory zone of the median eminence. Pulse generation by KNDy cell projections is probably at this level.
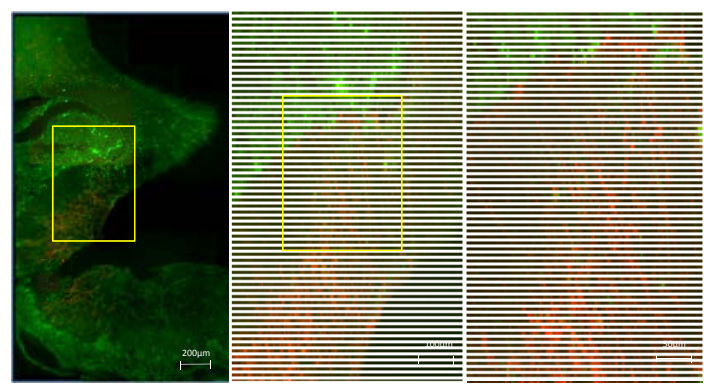

\section{Conclusion}

- KNDY cells of the arcuate nucleus project to the median eminence and could cause GnRH release at this level.

- Either KNDy cells or Glutamate cells (or both) could constitute the 'pulse generator, based on c-Fos activity at the time of a secretory pulse. GnRH cells do not appear to be activated at the level of the soma when a pulse episode of $\mathrm{GnRH}$ release occurs. 